\title{
Exploring Hotel Customers' Green Decision-Making Processes
}

\author{
Chieh-Heng Ko \\ Department of Hospitality Management, College of Tourism and Hospitality, Da-Yeh University, Taiwan \\ Email: chko@mail.dyu.edu.tw
}

How to cite this paper: Ko, C.-H. (2021) Exploring Hotel Customers' Green DecisionMaking Processes. Open Access Library Journal, 8: e7484.

https://doi.org/10.4236/oalib.1107484

Received: April 30, 2021

Accepted: June 4, 2021

Published: June 7, 2021

Copyright $\odot 2021$ by author(s) and Open Access Library Inc.

This work is licensed under the Creative Commons Attribution International License (CC BY 4.0).

http://creativecommons.org/licenses/by/4.0/

\section{(c) (i) Open Access}

\begin{abstract}
This study examined hotel customers' eco-friendly decision-making processes. Specifically, the current study tested the relationships among attitude toward green behaviors (ATGB), overall image (OI), visit intention (VI), word-ofmouth intention (WOMI), and willingness to pay more (WPM) by considering the effects of gender and age in a green hotel context. The results of structural equation analyses showed that OI is a positive function of ATGB and that OI significantly affects VI, WOMI, and WPM. Additionally, the findings from a structural modeling comparison revealed that OI completely mediates the effect of ATGB on components of behavioral intentions. Subsequent tests for metric invariance demonstrated that the relationships among study variables were generally stronger among females and high age groups. However, only the paths from OI to VI, WOMI, and WPM in the gender group and from OI to WPM in the age group were statistically significant. Implications and future research issues were discussed.
\end{abstract}

\section{Subject Areas}

Tourism Economy

\section{Keywords}

Green Hotel, Attitudes toward Green Behaviors, Overall Image, Gender, Age

\section{Introduction}

For the last few decades, concerns about environmental degradation have been increasing. As consumers have been recognizing the importance of protecting our environment, environmentalism has become a major issue in the marketplace. 
Increasingly aware of the seriousness of environmental problems, customers are becoming more ecologically conscious and are seeking to purchase eco-friendly products and services, preferring firms that favor environmental practices. In the lodging industry, following ecological initiatives such as the International Hotels Environmental Initiatives (IHEI) in 1993, there have been growing efforts to green the hotel industry by reducing energy and water consumption, local/non-durable goods, and emissions released into the air, water, or soil. That is, greening of the hotel industry is the process of developing new ways of doing business that reduce environmental harm and make use of waste streams [1]. This green movement has improved many hotel firms' ecological performances, reducing their operational costs and enhancing their corporate images [2].

A green hotel is an environmentally friendly hotel establishment that practices green principles and programs (e.g., water and energy savings or the reduction of solid waste and emissions) to help save the environment as well as to improve the hotel's effectiveness (e.g., cost-saving). The term, "green" is alternatively called "eco-friendly", "environmentally responsible", or "environmentally friendly" [3]. As Manaktola and Jauhari [4] stated, the number of customers seeking green hotel properties has grown. Marketing its environmentally friendly practices can be an effective strategy for a hotel looking to change its position and achieve competitiveness in the lodging industry [4].

Previous research in marketing and consumer behavior indicated that the overall image (OI) of a firm plays a critical role in buying behaviors [5]. However, no studies to date have been carried out to investigate the OI of a green hotel and its role in forming behavioral intentions. In addition, although researchers agree that customers' attitudes toward green behaviors (ATGB) in their everyday lives are a significant factor in determining eco-friendly purchasing [4], to the best of the authors' knowledge, no research has focused on the role of ATGB in the decision-making process given its relationship with OI. Furthermore, even though the impact of gender and age on decision-making has been extensively tested in various marketing and green consumption settings [6], little attempt has been made to identify whether these demographic characteristics affect behavioral intentions in a green hotel setting.

Accordingly, to enhance our understanding of hotel customers' eco-friendly decision-making, this study attempted to develop and test a model that investigated the relationships among ATGB, OI, and behavioral intentions such as visit intention (VI), word-of-mouth intention (WOMI), and willingness to pay more (WPM). The study also examined how differences in gender and age affect the formation of behavioral intentions using group comparisons in a green hotel context. The remainder of the current study is organized as follows. The literature, including theoretical support for study hypotheses, is reviewed and discussed in the next section. Then, methodology and results are presented. Finally, the implications and limitations of the current study findings and some directions for future study are discussed. 


\section{Literature Review}

\subsection{Behavioral Intentions}

Building customers' positive intentions, which eventually contribute to increasing customer retention rates and profits, is an important goal of every hospitality business [7]. Given this, many practitioners and academics in various fields have studied the creation and benefits of customers' favorable behavioral intentions [8]. Fishbein and Ajzen [9] initially described behavioral intentions as the most accurate predictors of actual behavior when examining individuals' careful decision-making processes using a theory of reasoned action. In a similar manner, Oliver [10] conceptualized behavioral intentions, which are surrogate indicators of behavior, as one's affirmed likelihood to perform a certain action. Intentions include plans or willingness to repurchase services or products from a company, to recommend the company (or to say positive things about the company), and to pay premium prices for its products [8]. Consistent with these previous studies, in this study behavioral intentions refer to hotel customers' affirmed likelihoods of visiting a green hotel, of engaging in a positive word-of-mouth (WOM) behavior, and of paying more for the green hotel.

\subsection{Overall Image}

The concept of a firm's image has drawn increasing attention from both academia and industry, as it is believed to play a critical role in customers' decisionmaking processes. Emphasizing the significance of understanding image development, numerous researchers across fields have attempted to identify the driving forces of OI and to determine its impact on buying behaviors [11]. To date, an exact definition of OI has been elusive, and researchers have defined it in various ways. Some destination researchers described OI as the sum of beliefs, thoughts, and impressions that individuals may have about a place [12]. Bloemer and Ruyter [13] conceptualized it as the complex of consumers' total perceptions of the salient attributes of a firm. They believed OI to be a more evaluative concept about the functions of attributes. Assael [14] provided one of the most concrete definitions of OI as a consumer's total perceptions of a product (or a firm) shaped by processing information from diverse sources. Although researchers define this concept somewhat differently, a close look at the descriptions of OI seems to indicate the common thread that forming an image of an object or place is a perceptual and cognitive process. In this study, therefore, OI refers to hotel customers' overall perceptions of a green hotel, formed by processing information and by prior or vicarious knowledge about a green hotel and its attributes.

The early works on image theory suggested that an individual's behavior is based on a psychological or distorted representation of objective reality that exists in the individual's mind [15]. In other words, people's behaviors are more likely to be determined by an image than by objective reality [15]. Similarly, in consumer behavior research, Oliver [10] found that consumers frequently devel-oped an attitude based on prior or current information of a product (or a pro- 
vider) without actual consumption experiences. These customers often increased their biases for or against the provider based on its image in the marketplace. These customers' attitudes, generated through these cognitive processes, contributed to the building of their intentions [10].

Numerous empirical studies have supported the influence of OI on customers' decision-making processes [5] [16]. Examining the role of store image, Prendergast and Man [17] found that a firm's image influences customers' behavioral intentions. In their destination study, Lin et al. [5] reported that a favorable OI of a specific destination reinforces travelers' preferences for that destination. Ryu et al.'s [16] findings also supported the relationship between OI and behavioral intentions. The results of their empirical investigation in the hospitality setting revealed that a firm's overall image has a critical role in forming behavioral intentions. In their study, image has a direct and indirect effect on intentions. Overall, the existing literature suggests a positive association between OI and behavioral intentions.

\subsection{Attitude toward Green Behaviors}

Over the last few decades, protecting the environment has been a major issue in our society. Recognizing the seriousness of ecological problems, people have become increasingly environmentally conscious. This ecological awareness has led an increasing number of individuals to engage in environmentally friendly behaviors in their everyday lives [18]. Amyx et al. [19] related the perceived importance of the environment to the degree to which individuals express their consciousness of environmental issues. In conceptualizing the perceived importance of the environment as the primary indicator of attitudes toward environmentally compatible behaviors, Laroche et al. [18] determined the levels of these attitudes by whether individuals considered eco-friendly behaviors to be essential to themselves or the entire society. This ATGB mainly involves the perceived importance or inconvenience of environmental consciousness, the severity of environmental problems, and the level of responsibility of corporations [18]. In other words, individuals' ATGB can be established by the level of their awareness of these dimensions of ATGB for themselves and for society as a whole.

Some researchers pointed out that only a small portion of environmentally conscious customers actually purchases eco-friendly products in the marketplace because of high monetary and non-monetary costs and inconvenience [20]. However, numerous findings indicated that more environ-mental concern tends to result in more environmentally friendly buying behaviors [4]. For instance, Laroche et al. [18] found that ecologically conscious customers who have a positive ATGB intend to spend more to consider ecological issues. In exploring consumer attitudes and behaviors toward green practices in the lodging industry, Manaktola and Jauhari [4] verified that customers with ecological concerns prefer to make eco-friendly purchases. These research findings emphasized the significant role of ATGB in the decision-making process. 
As stated earlier, awareness of the environment has increased substantially. Many individuals with a positive ATGB believe themselves to be environmentalists and expressing their willingness to make a special effort to buy a product or service from companies that follow environmental practices [21]. These ecologically conscious customers, who are willing to change their buying behaviors for the environment, build more favorable images of firms that try to protect the environment. Consequently, although the relationship between ATGB and OI has not been explored in the previous literature, it would be true that the link is positive and significant. This is also based on the idea that as knowledge or information of a green firm increases through various media and advertisements, customers with a favorable ATGB can more easily form a positive OI of that green firm.

\subsection{Gender}

Most of the studies of gender differences in social behavior are based on social role theory and evolutionary psychology. Assuming that individuals are passive holders of the roles given to them, social role theory indicates that males and females are socialized in a different way and play different roles in our society [22] [23]. Evolutionary psychology also accounts for sex differences in human behavior. In addition to elucidating the gender-related dissimilar adaptive problems encountered in the past, evolutionary psychology indicates that gender plays a significant role in sustaining individuals' patterns of social behaviors given males' and females' fitness interests [22] [23]. These theories are believed to be the primary concepts employed by researchers to explicate gender differences in patterns, dispositions, and behaviors in various contexts [22] [23].

The impact of gender on buying behavior is generally acknowledged in marketing and consumer behavior studies. Specifically, many researchers have extensively investigated gender differences in consumption [24]. Some researchers suggested that, compared to males, females involved in purchasing activities are more likely to pay attention to personal interactions and interpersonal relationships [25]. Similarly, in their empirical study explaining the formation of customer loyalty in the automobile industry, Homburg and Giering [24] found that the relationship between satisfaction with sales process and repurchase intentions is strongly influenced by gender. In their study, the link was stronger for females than males. Because of existing gender role, males and females also significantly differ in attitudes [25]. According to Eagly [26], females are more concerned about the welfare of others than males are. In examining customers' intentions to pay for environmentally friendly products, Laroche et al. [18] empirically verified that women were more concerned about the environment than men and were willing to pay more for green products. Consistent with this, findings in numerous environ-mental consumption studies have indicated that women tend to be more ecologically conscious and more frequently make eco-friendly purchasing decisions than men do [27]. This tendency can be explained by the 
social role theory that females tend to be more responsible and obedient and that males tend to be more self-reliant and aggressive [28].

\subsection{Age}

Age is another important determinant of buying behaviors. Thus, the impact of age on purchasing behaviors has attracted considerable research attention. The results in the previous literature about the effect of age on decision-making are mixed. Whereas younger individuals are likely to be innovative when adopting a new product or service or communicating with a new provider, older people are more likely to be conservative about a new product or service and the interaction with a new provider [29]. A theory related to information processing indicated that younger individuals tend to search more for new or alternative information [6]. On the other hand, older people tend to rely more on existing information because information processing capacities decline with age [6]. Most studies supporting a significant moderating role of age in the marketing and consumer behavior literature posited and tested the effect of age on consumer behaviors based on these theories associated with innovativeness and information processing [6] [29]. Overall, these findings indicated that the customer decision-making process is not as simple as it may seem. It is strongly influenced by age.

The important role of age in the environmental purchasing process is also identified in the previous literature [30]. Many researchers agreed that age exerts a significant influence on eco-friendly purchasing [31]. Customers who frequently engage in environmentally friendly purchasing behaviors are older than average [32]. Similarly, in developing a profile of environmentally conscious customers, Roberts [20] suggested that older and younger age groups of customers have different tendencies to make ecologically conscious purchasing decisions. He found evidence that compared to younger customers, older customers tended to be more ecologically conscious and to have a greater propensity to decide to make an eco-friendly purchase. Given the empirical evidence in these studies of environmentally friendly consumption, we expect age to have an important role in the formation of behavioral intentions. Specifically, the relationships between antecedents of intentions and intentions would be stronger for high age groups than low age groups.

\subsection{Hypotheses}

Based on the aforementioned theoretical framework, the current study formulated the following hypotheses:

H1. ATGB has a positive influence on OI.

$\mathrm{H} 2$. OI has a positive influence on VI.

H3. OI has a positive influence on WOMI.

$\mathrm{H} 4$. OI has a positive influence on WPM.

H5a. The impact of ATGB on OI will be stronger for females than for males.

H5b. The impact of OI on VI will be stronger for females than for males. 
H5c. The impact of OI on WOMI will be stronger for females than for males.

H5d. The impact of OI on WPM will be stronger for females than for males.

H6a. The impact of ATGB on OI will be stronger for high age group than for low age group.

H6b. The impact of OI on VI will be stronger for high age group than for low age group.

H6c. The impact of OI on WOMI will be stronger for high age group than for low age group.

H6d. The impact of OI on WPM will be stronger for high age group than for low age group.

\section{Methodology}

\subsection{Measures}

The questionnaire in this study was developed from a thorough literature review. The questionnaire was refined based on a review by hospitality and business experts' and was then pilot-tested to ensure the reliability and validity of the scales. In addition to a detailed description of a green hotel in the instructions, the questionnaire included three sections. The first section included questions regarding customers' attitudes toward eco-friendly behaviors in their everyday lives. Specifically, the severity of environmental problems, the inconvenience of being environmentally friendly, the importance of being environmentally friendly, and the level of responsibility of corporations were all employed to assess ATGB using a 7-point Likert-type scale. The second section included measures for OI, VI, WOMI, and WPM, which were adopted and modified from Maxham and Netemeyer [32]. In particular, three items for OI, three items for VI, two items for WOMI, and three items for WPM, with a 7-point Likert-type scale ranging from 1 (Strongly disagree) to 7 (Strongly agree) were used to assess these constructs. The last section contained questions about demographic information and a question asking if a survey participant has ever stayed at a green hotel.

\subsection{Data Collection and Sample Profile}

The sample in this study was composed of general hotel customers in Taiwan who were 18 years of age and older. An online survey was used as a data collection method to effectively reach a general population sample. The questionnaire was distributed to 300 lodging customers in Taiwan through the survey system of an online market research firm. In the opening instruction of this survey, a detailed and straightforward explanation of a green hotel including its green practices (e.g., waste and water recycling, energy conservation, avoidance of disposable goods, donation of usable items to charity, pollution remediation, and organic foods) was given. Survey participants were asked to thoroughly read the description before completing the survey questionnaire. After removing incomplete and unusable responses, a total of 213 usable surveys were kept, resulting in 
a usable response rate of $71 \%$. In the usable sample of 213 , approximately $46.6 \%$ respondents were male and $53.4 \%$ were female. Their ages ranged from 19 to 81 years with an average age of 44.4 years. The majority had a relatively high education level (89.2\% had at least a college degree). About $52.3 \%$ of the respondents said that they stay in a hotel at least 2 - 5 times a year, and $18.3 \%$ indicated that they stay in a hotel 6 - 10 times a year. Approximately $68.3 \%$ of the respondents reported NT $\$ 39,999$ or less in household income, and $31.7 \%$ indicated an income of NT\$70,000 or greater. Among the survey participants, $76.1 \%$ indicated that they have stayed at a green hotel; $12.6 \%$ described that they have never stayed at a green hotel; and $11.3 \%$ reported that they are not sure whether they ever stayed at a green hotel.

\subsection{Data Analysis}

Based on Anderson and Gerbing's [33] two-step approach, the current study assessed the adequacy of measurements using a confirmatory factor analysis (CFA) and tested the hypothesized relationships among study constructs by employing a structural equation modeling (SEM). SPSS and AMOS5 were used as data analysis tools. Last, tests for metric invariances were employed to assess the group differences in the proposed model (i.e., gender and age).

\section{Analysis}

\subsection{Confirmatory Factor Analysis Results}

Prior to data analysis, an evaluation of the assumptions was performed. The results of this evaluation revealed that the study variables were significantly negatively skewed. A square root transformation was used on these variables to reduce the skewness and improve normality and linearity. After completing the transformation, a measurement model was assessed by using CFA with the maximum likelihood estimation method. The adequacy of the five-factor measurement model was evaluated by examining its goodness-of-fit indices, its reliability, and the convergent and discriminant validity of the construct. The results of the CFA were shown in Table 1 . The overall goodness-of-fit indices showed that the five-factor model had an acceptable fit with the data $\left(\chi^{2}=209.042\right.$, d.f. $=79, p<$ 0.001$, RMSEA $=0.067, \mathrm{CFI}=0.981, \mathrm{NFI}=0.970)$. All items were significantly loaded above 0.73 on their specified latent construct $(p<0.01)$. The construct reliabilities for ATGB, OI, VI, WOMI, and WPM were 0.912, 0.919, 0.744, 0.952, and 0.898 , respectively. These values exceeded the recommend threshold suggested by Bagozzi and Yi [34], indicating the internal consistency of items for each construct. A variance extracted test was employed to examine convergent and discriminant validity. The results showed that all the average variance extracted (AVE) values were above the suggested cutoff of 0.50 and that these values were greater than the square of the correlation between any pair of factors. These findings confirmed convergent and discriminant validity. 
Table 1. Correlations and squared correlations among study constructs and AVE.

\begin{tabular}{|c|c|c|c|c|c|c|}
\hline $\begin{array}{l}\text { Correlations among } \\
\text { study constructs } \\
\text { (squared) }\end{array}$ & & & & & & \\
\hline Measure & ATGB & OI & VI & WOMI & WPM & AVE \\
\hline ATGB & 1.000 & & & & & 0.734 \\
\hline OI & $\begin{array}{c}0.345 \\
(0.119)\end{array}$ & 1.000 & & & & 0.912 \\
\hline VI & $\begin{array}{c}0.319 \\
(0.102)\end{array}$ & $\begin{array}{c}0.747 \\
(0.558)\end{array}$ & 1.000 & & & 0.712 \\
\hline WOMI & $\begin{array}{c}0.231 \\
(0.053)\end{array}$ & $\begin{array}{c}0.778 \\
(0.605)\end{array}$ & $\begin{array}{c}0.728 \\
(0.530)\end{array}$ & 1.000 & & 0.951 \\
\hline WPM & $\begin{array}{c}0.011 \\
(0.000)\end{array}$ & $\begin{array}{c}0.470 \\
(0.221)\end{array}$ & $\begin{array}{c}0.518 \\
(0.268)\end{array}$ & $\begin{array}{c}0.564 \\
(0.318)\end{array}$ & 1.000 & 0.893 \\
\hline Construct reliability & 0.912 & 0.919 & 0.744 & 0.952 & 0.898 & \\
\hline Mean & 5.721 & 5.675 & 5.303 & 4.914 & 4.001 & \\
\hline SD & 1.483 & 1.242 & 1.260 & 1.579 & 1.665 & \\
\hline $\begin{array}{l}\text { Model measurement fit } \\
x^{2}=209.042 \text {, d.f. }=79, \\
p<0.001\end{array}$ & & & & & & \\
\hline $\begin{array}{l}\text { RMSEA }=0.067 \\
\mathrm{NFI}=0.970\end{array}$ & & & & & & \\
\hline
\end{tabular}

Note: ATGB = attitude toward green behaviors; OI = overall image; VI = visit intention; WOMI = word-of-mouth intention; WPM = willingness to pay more.

\subsection{Structural Model Comparison and Results}

As a next step, SEM was tested. The results of maximum likelihood estimation suggested that the model fit to the data well $\left(\chi^{2}=266.555\right.$, d.f. $=83, p<0.001$, RMSEA $=0.077, \mathrm{CFI}=0.973, \mathrm{NFI}=0.962$ ). All of the links were significant and positive. Previous research indicated that customers' positive attitudes toward environmentally friendly behaviors impacted their buying behaviors [18]. Thus, after the satisfactory results of the model evaluation, the proposed model was re-estimated by adding three direct paths from the independent variable (ATGB) to the outcome variables (VI, WOMI, and WPM). Although this revised model had an adequate fit to the data $\left(\chi^{2}=261.236\right.$, d.f. $=80, p<0.001$, RMSEA $=$ 0.076 , CFI $=0.975$, NFI $=0.964)$, the added paths were insignificant $(p>0.01)$. In addition, there was no significant chi-square difference between this model and the proposed model $\left(\Delta \chi^{2}=5.319, \Delta\right.$ d.f. $\left.=3\right)$. Therefore, the original theoretical model was retained for further analyses. Figure 1 shows this conceptual model.

The first four hypotheses were tested. As shown in Table 2, the results supported the hypothesized relationships among ATGB, OI, VI, WOMI, and WPM. 


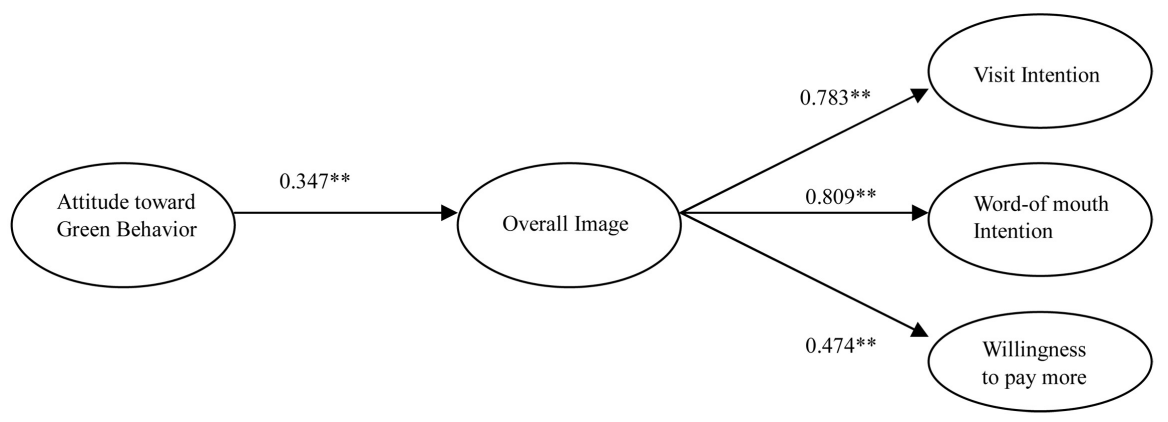

Figure 1. Results of structural equation model $(\mathrm{N}=213) .{ }^{\star} p<0.01$.

Table 2. Standardized maximum-likelihood parameter estimates.

\begin{tabular}{cccc}
\hline Paths & Coefficients & $t$-values & Hypotheses \\
\hline ATGB $\rightarrow$ OI & 0.347 & 6.768 & H1: supported \\
OI $\rightarrow$ VI & 0.783 & 14.552 & H2: supported \\
OI $\rightarrow$ WOMI & 0.809 & 21.594 & H3: supported \\
OI $\rightarrow$ WPM & 0.474 & 9.505 & H4: supported \\
Goodness-of-fit statistics: & & & \\
$\chi^{2}=266.555$, d.f. $=83, p<0.001$ & & \\
$\left(\chi^{2} /\right.$ d.f. $\left.=3.212\right)$ & & \\
RMSEA $=0.077$ & & \\
CFI $=0.973$ & & \\
NFI $=0.962$ & & \\
$R^{2}($ adjusted $):$ & & \\
OI $=0.120$ & & \\
VI $=0.614$ & & \\
WOMI $=0.654$ & & & \\
WPM $=0.225$ & & & \\
\end{tabular}

Note: $\mathrm{ATGB}=$ attitude toward green behaviors; $\mathrm{OI}=$ overall image; $\mathrm{VI}=$ visit intention; $\mathrm{WOMI}=$ word-of-mouth intention; WPM = willingness to pay more. $p<0.01$.

Consequently, hypotheses H1, H2, H3, and H4 were supported. Specifically, customers' attitudes toward environmentally friendly behaviors were a significant predictor of $\mathrm{OI}(\mathrm{H} 1: \beta=0.347, t=6.768, p<0.01)$, and OI was significantly and positively associated with VI (H2: $\beta=0.783, t=14.552, p<0.01)$, WOMI (H3: $\beta=0.809, t=21.594, p<0.01$ ), and WPM (H4: $\beta=0.474, t=9.505, p<$ 0.01 ). The link between OI and WOMI was relatively stronger than the causal paths linking OI and VI and OI and WPM. The predictor of OI explained about $12.0 \%$ of the total variance in OI. OI accounted for approximately $61.4 \%$ of the variance in VI, $65.4 \%$ of the variance in WOMI, and $22.5 \%$ of the variance in WPM.

\subsection{Tests for Group Differences (Gender and Age)}

Prior to conducting a test for metric invariance, the respondents were split into 
male and female groups and into high and low age groups. The sizes of the male and female groups were 173 and 198, respectively. Age grouping was done by a median-split. The median value was 41 years with a total of 13 cases at the median. These cases were excluded for more accurate analyses. The group below the median included 177 subjects, and the group above the median contained 181 subjects. The groups were named as low and high age groups, respectively, in that the individuals in the first age group are younger than the median and the individuals in the second group are older than the median. That is, the age groups were named as low and high age groups compared to the median.

As a next step, the equality of factor loadings across groups was tested (measurement invariance). First, CFA was conducted without constraining any factor loading across groups, and this non-restricted model was compared to the full-metric invariance of the CFA model in which all factor loadings for study constructs were constrained to be equal between groups. Table 3 shows the results of the measurement invariance test for the gender and age groups. For both gender and age groups, full-metric invariance was supported in that the chi-square difference between the non-restricted model and full-metric invariance model was not significant (gender: $\Delta \chi^{2}(10)=11.844, p>0.01$; age: $\Delta \chi^{2}(10)=13.602$, $p>0.01)$. The findings imply that the impact of probable variation across gender and age groups in the measurement structure is trivial and insignificant.

To conduct the multiple sample analysis, SEM was run by adding the hypothesized paths between the study constructs. As shown in Table 3, this baseline model for gender and age groups showed a good fit to the data (gender: $\chi^{2}=$

Table 3. Measurement invariance test.

\begin{tabular}{|c|c|c|c|c|c|c|c|c|}
\hline Groups & Models & $x^{2}$ & d.f. & RMSEA & CFI & NFI & $\mathrm{D} \chi^{2}$ & $\begin{array}{l}\text { Full-metric } \\
\text { invariance }\end{array}$ \\
\hline \multirow[t]{3}{*}{$\begin{array}{l}\text { Gender } \\
\text { groups }\end{array}$} & $\begin{array}{c}\text { Non-restricted } \\
\text { model }\end{array}$ & 318.144 & 158 & 0.052 & 0.976 & 0.954 & $\begin{array}{c}\mathrm{D} \chi^{2}(10)= \\
11.844\end{array}$ & Supported \\
\hline & & & & & & & $\begin{array}{c}p>0.01 \\
\text { (insignificant) }\end{array}$ & \\
\hline & $\begin{array}{c}\text { Full-metric } \\
\text { invariance } \\
\left(\mathrm{L}(\mathrm{X}) \mathrm{Y}=\mathrm{IN}^{\mathrm{a}}\right)\end{array}$ & 329.988 & 158 & 0.051 & 0.976 & 0.952 & & \\
\hline \multirow[t]{3}{*}{$\begin{array}{l}\text { Age } \\
\text { groups }\end{array}$} & & 338.411 & 168 & 0.057 & 0.973 & 0.950 & $\begin{array}{c}\mathrm{D} \chi^{2}(10)= \\
13.602\end{array}$ & Supported \\
\hline & & & & & & & $\begin{array}{c}p>0.01 \\
\text { (insignificant) }\end{array}$ & \\
\hline & $\begin{array}{c}\text { Full-metric } \\
\text { invariance } \\
\left(\mathrm{L}(\mathrm{X}) \mathrm{Y}=\mathrm{IN}^{\mathrm{a}}\right)\end{array}$ & 352.013 & 158 & 0.055 & 0.972 & 0.948 & & \\
\hline
\end{tabular}

$\mathrm{IN}=$ invariance. 
392.201, d.f. $=176, p<0.001$, RMSEA $=0.058, \mathrm{CFI}=0.967, \mathrm{NFI}=0.943$; age: $\chi^{2}=414.214$, d.f. $=176, p<0.001, \mathrm{RMSEA}=0.062$, CFI $=0.964$, NFI $\left.=0.939\right)$. The equality of a specific path across groups was assessed by constraining the particular parameter of interest to be equal sequentially (nested models). In particular, the baseline model was compared with a series of nested models, each with a specific parameter constraint between groups, by using a chi-square difference test. This test determined whether the differences in the parameter of interest across groups were statistically significant. The findings from the invariance test and the chi-square difference test are summarized in Table 4.

The link between ATGB and OI was not significantly different between genders $\left(\Delta \chi^{2}(1)=2.550, p>0.05\right)$. Thus, H5a was not supported. Regarding the paths from OI to its outcome variables, there were significant differences between males and females $\left(\Delta x_{\mathrm{OI} \rightarrow \mathrm{VI}}^{2}(1)=4.371, p<0.05 ; \Delta x_{\mathrm{OI} \rightarrow \text { WOMI }}^{2}(1)=\right.$ 5.277, $\left.p<0.05 ; \Delta x_{\mathrm{OI} \rightarrow \mathrm{WPM}}^{2}(1)=8.303, p<0.01\right)$. As hypothesized, the effects of OI on VI, WOMI, and WPM were greater in the female group $\left(\beta_{\mathrm{OI} \rightarrow \mathrm{VI}}=0.791\right.$, $t=12.482, p<0.01 ; \beta_{\mathrm{OI} \rightarrow \mathrm{WOMI}}=0.805, t=16.455, p<0.01 ; \beta_{\mathrm{OI} \rightarrow \mathrm{WMP}}=0.496, t=$ 7.522, $p<0.01)$ than in the male group $\left(\beta_{\mathrm{OI} \rightarrow \mathrm{VI}}=0.727, t=10.314, p<0.01\right.$; $\left.\beta_{\mathrm{OI} \rightarrow \mathrm{WOMI}}=0.763, t=13.690, p<0.01 ; \beta_{\mathrm{OI} \rightarrow \mathrm{WMP}}=0.348, t=4.660, p<0.01\right)$. Accordingly, $\mathrm{H} 5 \mathrm{~b}, \mathrm{H} 5 \mathrm{c}$, and $\mathrm{H} 5 \mathrm{~d}$ were supported. For the age groups, the path from ATGB to OI was not significantly different $\left(\Delta \chi^{2}(1)=0.559, p>0.05\right)$. In

Table 4. Invariance tests of the structural models for gender and age groups.

\begin{tabular}{|c|c|c|c|c|c|c|}
\hline Gender & & & & & & \\
\hline \multirow[t]{2}{*}{ Paths } & \multicolumn{2}{|l|}{ Male } & \multicolumn{2}{|l|}{ Female } & \multirow[t]{2}{*}{$\begin{array}{c}\text { Baseline model } \\
\text { (freely estimated) }\end{array}$} & \multirow[t]{2}{*}{$\begin{array}{c}\text { Nested model } \\
\text { (constrained to be equal) }\end{array}$} \\
\hline & Coefficients & $t$-values & Coefficients & $t$-values & & \\
\hline ATGB $\rightarrow$ OI & 0.219 & 2.841 & 0.377 & 5.451 & $\chi^{2}(176)=392.201$ & $\chi^{2}(177)=394.451^{\mathrm{a}}$ \\
\hline $\mathrm{OI} \rightarrow \mathrm{VI}$ & 0.727 & 10.314 & 0.791 & 12.482 & $\chi^{2}(176)=392.201$ & $\chi^{2}(177)=396.572^{b}$ \\
\hline $\mathrm{OI} \rightarrow \mathrm{WOMI}$ & 0.763 & 13.690 & 0.805 & 16.455 & $\chi^{2}(176)=392.201$ & $\chi^{2}(177)=397.478^{c}$ \\
\hline $\mathrm{OI} \rightarrow \mathrm{WPM}$ & 0.348 & 4.660 & 0.496 & 7.522 & $\chi^{2}(176)=392.201$ & $\chi^{2}(177)=400.504^{\mathrm{d}}$ \\
\hline \multicolumn{7}{|l|}{ Age } \\
\hline \multirow[t]{2}{*}{ Paths } & Low age & & High age & & $\begin{array}{c}\text { Baseline model } \\
\text { (freely estimated) }\end{array}$ & $\begin{array}{c}\text { Nested model } \\
\text { (constrained to be equal) }\end{array}$ \\
\hline & Coefficients & $t$-values & Coefficients & $t$-values & & \\
\hline $\mathrm{ATGB} \rightarrow \mathrm{OI}$ & 0.374 & 5.135 & 0.376 & 5.134 & $\chi^{2}(176)=414.214$ & $\chi^{2}(177)=414.773^{\mathrm{e}}$ \\
\hline $\mathrm{OI} \rightarrow \mathrm{VI}$ & 0.774 & 11.239 & 0.791 & 11.837 & $\chi^{2}(176)=414.214$ & $\chi^{2}(177)=417.018^{\mathrm{f}}$ \\
\hline OI $\rightarrow$ WOMI & 0.799 & 15.566 & 0.826 & 16.630 & $\chi^{2}(176)=414.214$ & $\chi^{2}(177)=417.377^{g}$ \\
\hline $\mathrm{OI} \rightarrow \mathrm{WPM}$ & 0.368 & 5.038 & 0.563 & 8.551 & $\chi^{2}(176)=414.214$ & $\chi^{2}(177)=422.703^{\mathrm{h}}$ \\
\hline
\end{tabular}

Note $1: \mathrm{ATGB}=$ attitude toward green behaviors; $\mathrm{OI}=$ overall image; $\mathrm{VI}=$ visit intention; WOMI = word-of-mouth intention; WPM = willingness to pay more. Note 2: Other goodness of fit indices of the baseline model for gender: RMSEA $=0.058$; CFI $=0.967$; NFI $=0.943$. Note 3: Other goodness of fit indices of the baseline model for age: RMSEA $=0.062$; CFI $=0.964$; NFI $=0.939 .{ }^{\mathrm{a}} \Delta \chi^{2}(1)=2.550, p>0.05$ (insignificant; H5a-not supported). ${ }^{\mathrm{b}} \Delta \chi^{2}(1)=4.371, p$ $<0.05$ (significant; H5b-supported). ${ }^{\mathrm{c}} \Delta \chi^{2}(1)=5.277, p<0.05$ (significant; H5c-supported). ${ }^{\mathrm{d}} \Delta \chi^{2}(1)=8.303, p<0.01$ (significant; H5d-supported). ${ }^{\mathrm{e}} \Delta \chi^{2}$ $(1)=0.559, p>0.05$ (insignificant; H6a-not supported). ${ }^{\mathrm{f}} \Delta \chi^{2}(1)=2.804, p>0.05$ (insignificant; H6b一not supported). ${ }^{\mathrm{g}} \Delta \chi^{2}(1)=3.163, p>0.05$ (insignificant; H6c-not supported). ${ }^{\mathrm{h}} \Delta \chi^{2}(1)=8.489, p<0.01$ (significant; H6d-supported). 
addition, the links between OI and VI $\left(\Delta \chi^{2}(1)=2.804, p>0.05\right)$ and between OI and WOMI $\left(\Delta \chi^{2}=3.163, p>0.05\right)$ across the low and high age groups were not statistically significantly different. Thus, H6a, H6b and H6c were not supported. The path from OI to WPM, however, was significantly different across age groups $\left(\Delta \chi^{2}(1)=8.489, p<0.01\right)$. Specifically, the path coefficient for the high age group was found to be greater than for the low age group (high age group: $b=$ $0.563, t=8.551, p<0.01$ vs. low age group: $\beta=0.368, t=5.038, p<0.01$ ), supporting H6d.

\section{Discussion and Implications}

The current study aimed to increase our understanding of the formation of behavioral intentions by considering the effects of gender and age in a green hotel context. The relations between ATGB and OI was explored; the roles of ATGB and OI in building VI, WOMI, and WPM were illustrated using a SEM approach that simultaneously explored the underlying relationships among the study constructs; and gender and age differences were empirically examined by applying the metric invariance test procedure. Although the strengths of some links did not statistically differ across gender and age groups (H5a, H6a, H6b, and H6c), the findings generally supported the hypothesized linkages among study constructs in the proposed conceptual model (H1-H4) and the hypothesized roles of gender and age in determining behavioral intentions (H5b-H5d and H6d).

\subsection{Impact of Attitudes and Overall Image}

Previous research on ATGB has primarily focused on the strength of its relationship with intentions to make environmentally friendly purchases. The current study integrated the OI of a green hotel establishment into the behavioral intentions model, illustrating the importance of its role in building not only VI but also WOMI and WPM. This study may be the first attempt to empirically test a relationship between ATGB and the OI of a green hotel and to assess the influence of this relationship on the components of behavioral intentions. The results of the SEM indicated that the proposed model had a good fit, and the adjusted coefficient of determination (adjusted $R^{2}$ ) indicated that the model predicted and explained customers' intentions to visit (0.614), to spread positive WOM (0.654), and to pay more (0.225) fairly well. In addition, ATGB accounted for about $12 \%$ of the total variance in OI. The unique contribution of the relationship between ATGB and OI to intentions adds a level of understanding of the decision-making process that has not been previously highlighted in marketing and consumer research. Consequently, researchers should consider the significant roles of these constructs to better comprehend customers' eco-friendly purchasing behaviors.

From a practical point of view, the study findings implied that customers who have favorable attitudes toward eco-friendly behaviors in their everyday lives and positive images of green hotels are willing to stay at a green hotel, to rec- 
ommend it, and to pay more. These current study results are already important enough to deserve marketers' attention. Accordingly, marketers working for a green hotel should try to simultaneously enhance people's green attitudes and their firm's image. In particular, consumers' ecological consciousness and ATGB are likely to be encouraged by accentuating the significance of environmental issues [35]. Thus, green hotel marketers should emphasize the importance of various environmental issues to current or potential customers by promoting green campaigns. In addition, marketers in a green hotel should develop effective strategies to promote their hotel's image. For example, marketers can advertise their ecological practices (e.g., recycling, water and energy conservation, avoidance of disposable goods, donation of usable items to charity, or reduction of emissions released into the air, water, and soil) to customers. Further, it is recommended that marketers actively present the specific attributes of a green hotel (e.g., nonchemical-based amenities, environmental cleaning, or availability of organic foods) to the public using multiple information sources. These efforts would effectively improve customers' favorable overall perceptions or images of a green hotel.

\subsection{Impact of Gender and Age}

This study may be one of only a few attempts to empirically assess the impacts of gender and age on intention formation in a green hotel context. As expected, the results indicated that although the ATGB and OI link did not differ, the path coefficients for the links between OI and the outcome variables were generally stronger for females. The findings were generally consistent with previous studies about gender differences in environmentally conscious behaviors [18]. However, for age groups, although all of the path coefficients among study constructs were stronger for the high age group, only the link between OI and WPM was statistically significantly different. Thus, the findings were partially consistent with the previous studies [20]. Overall, the present study implies that once female customers build an adequate level of OI of a green hotel, they are more willing to visit a green hotel and are more likely to engage in recommendations or positive WOM behaviors. In addition, female customers and older customers both have a stronger willingness to pay more for a green hotel. The current study contributes to the very limited literature on gender and age-related differences in hotel customers' decision-making. Researchers should not neglect the potential differences among gender and age groups when investigating eco-friendly pre/post-purchase decision-making processes.

From a practical standpoint, the findings also provide important information for green hotel marketers and advertisers about the characteristics of their target market. To increase its market share, a green hotel firm should actively make positioning efforts in the ecologically conscious market. In addition, in order to motivate eco-friendly customers to more frequently purchase environmentally conscious lodging, it is essential to emphasize the importance of individuals' 
ecological decisions and actions, and to provide encouraging feedback indicating that individuals have made a positive difference because of their decisions and actions [20]. This positive communication approach can improve the perceived effectiveness of these behaviors, which eventually boosts eco-friendly purchasing [20].

Marketers in a green hotel should also actively inform less environmentally conscious groups that eco-friendly purchasing exerts a positive influence on our environment, and convince them that protecting our environment is everyone's responsibility through various media and advertising campaigns. These efforts would motivate the greening of individuals' everyday habits and would eventually enhance their ecological purchasing decision-making. In other words, although costly in the short term, these endeavors would gradually turn less environmentally conscious people into green decision-makers when buying a hotel product in the long run.

\subsection{Mediating Role of Overall Image}

Some recent studies suggested that customers' eco-friendly attitudes and concerns are favoring environmentally friendly hotel businesses [36]. For instance, the Association of British Tour Operators (ABTA) (2008) found that travelers who perceive seriousness of the environmental problems are likely to stay in an ecofriendly hotel. Dalton et al. [36] identified that tourists' perceived importance of being environmentally friendly actively express a willingness to stay in an environmentally friendly hotel accommodation and to pay extra for the product, cooperating with renewable energy supply initiatives and possible resultant inconveniences. In addition, according to the results of a survey reported by Pennsylvania Department of Environmental Protection (PDEP) (2008), customers' attitudes contributed to enhancing their intentions to stay green properties. Further, Ryu, Han and Kim's [16] findings from the survey with 565 tourists indicated that about $40 \%$ of the participants who perceive severity of environmental problems would be willing to pay more for a green hotel property. Consistent with these recent studies, our findings indicated that ATGB had a significant role in forming behavioral intentions. However, the current study results also indicated that ATGB only indirectly affects behavioral intentions at an alpha level of 0.01 (VI: coefficient $_{\text {ATGB-OI-VI }}=0.272$; WOMI: coefficient $_{\text {ATGB-OI-WOMI }}=0.280$; and WPM: coefficient ATGB-OI-WPM $=0.164$ ) when the role of OI was taken into account. That is, relationships between ATGB and the components of behavioral intentions were fully mediated by OI. As stated earlier, the direct relationships between ATGB and the dimensions of behavioral intentions were not significant in the revised model $(p>0.01)$ because OI acted as a complete mediator. These findings implied that a favorable ATGB tailors a favorable OI of a firm, and this positive image leads to more environmentally friendly decision-making. Accordingly, green hotel managers must understand the significance of improving the hotel's OI to maximize the effects of ATGB on intentions to visit, recommend, 
and pay more.

\section{Conflicts of Interest}

The author declares no conflicts of interest regarding the publication of this paper.

\section{References}

[1] Wiserearth (2008) Greening of Industry. http://www.wiser-earth.org/aof/764

[2] Yim, W. and Penny, K. (2007) The Use of Environmental Management as a Facilities Management Tool in the Macao Hotel Sector. Facilities, 25, 286-295. https://doi.org/10.1108/02632770710753325

[3] Pizam, A. (2009) Green Hotels: A Fad, Ploy or Fact of Life? International Journal of Hospitality Management, 28, 1. https://doi.org/10.1016/j.ijhm.2008.09.001

[4] Manaktola, K. and Jauhari, V. (2007) Exploring Consumer Attitude and Behavior towards Green Practices in the Lodging Industry in India. International Journal of Con-temporary Hospitality Management, 19, 364-377.

https://doi.org/10.1108/09596110710757534

[5] Lin, C., Morais, D.B., Kerstetter, D.L. and Hou, J. (2007) Examining the Role of Cognitive and Affective Image in Predicting Choice across Natural, Developed, and Theme-Park Destinations. Journal of Travel Research, 46, 183-194. https://doi.org/10.1177/0047287507304049

[6] Evanschitzky, H. and Wunderlich, M. (2006) An Examination of Moderator Effects: The Four Stage Loyalty Model. Journal of Service Research, 8, 330-345. https://doi.org/10.1177/1094670506286325

[7] Lewis, R.C. and Chambers, R.E. (2000) Marketing Leadership in Hospitality. Third Edition, Wiley, New York.

[8] Namkung, Y. and Jang, S. (2007) Does Food Quality Really Matter in Restaurant? Its Impact on Customer Satisfaction and Behavioral Intentions. Journal of Hospitality \& Tourism Research, 31, 387-410. https://doi.org/10.1177/1096348007299924

[9] Fishbein, M.A. and Ajzen, I. (1975) Belief, Attitude Intention and Behavior: An Introduction to Theory and Research. Addison-Wesley, Reading.

[10] Oliver, R.L. (1997) Satisfaction: A Behavioral Perspective on the Consumer. McGraw-Hill, New York.

[11] Chen, C. and Tsai, D.C. (2007) How Destination Image and Evaluative Factors Affect Behavioral Intentions? Tourism Management, 28, 1115-1122. https://doi.org/10.1016/j.tourman.2006.07.007

[12] Kotler, P., Haider, D.H. and Rein, I. (1993) Marketing Places: Attracting Investment, Industry, and Tourism to Cities, States and Nations. The Free Press, New York.

[13] Bloemer, J. and Ruyter, K. (1998) On the Relationship between Store Image, Store Satisfaction and Store Loyalty. Enropean Journal of Marketing, 32, 499-513. https://doi.org/10.1108/03090569810216118

[14] Assael, H. (1984) Consumer Behavior and Marketing Action. Kent, Boston. Association of British Tour Operators 2008.

[15] Myers, J.G. (1968) Consumer Image and Attitude. Institute of Business and Economic Research, University of California, Berkeley.

[16] Ryu, K., Han, H. and Kim, T. (2007) The Relationships among Overall Quick-Casual 
Restaurant Image, Perceived Value, Customer Satisfaction, and Behavioral Intentions. International Journal of Hospitality Management, 27, 459-469.

https://doi.org/10.1016/j.ijhm.2007.11.001

[17] Prendergast, G. and Man, H.W. (2002) The Influence of Store Image on Store Loyalty in Hong Prepositions. Journal of Marketing, 46, 92-101.

[18] Laroche, M., Bergeron, J. and Barbaro-Forleo, G. (2001) Targeting Consumers Who Are Willing to Pay More for Environmentally Friendly Products. Journal of Consumer Marketing, 18, 503-520. https://doi.org/10.1108/EUM0000000006155

[19] Amyx, D.A., Dejong, P.F., Lin, X., Chakraborty, G. and Wiener, J.L. (1994) Influencers of Purchase Intentions for Ecologically Safe Products: An Exploratory Study. In: Park, C.W., et al., Eds., AMA Winter Educators' Conference Proceedings 5, American Marketing Association, Chicago, 341-347.

[20] Roberts, J.A. (1996) Green Consumers in the 1990s: Profile and Implications for Advertising. Journal of Business Research, 36, 217-231. https://doi.org/10.1016/0148-2963(95)00150-6

[21] Donaton, S. and Fitzerald, K. (1992) Polls Show Ecological Concern Is Strong. Advertising Age, 63, 3.

[22] Archer, J. (1996) Sex Differences in Social Behavior: Are Social Role and Evolutionary Explanations Compatible? American Psychologist, 51, 909-917. https://doi.org/10.1037/0003-066X.51.9.909

[23] Buss, D. (1996) The Evolutionary Psychology of Human Social Strategies. In: Higgins, E.T. and Kruglanski, A.W., Eds., Social Psychology: Handbook of Basic Principles, The Guilford Press, New York, 3-38.

[24] Homburg, C. and Giering, A. (2001) Personal Characteristics as Moderators of the Relationship between Customer Satisfaction and Loyalty: An Empirical Analysis. Psychology \& Marketing, 18, 43-66. https://doi.org/10.1002/1520-6793(200101)18:1<43::AID-MAR3>3.0.CO;2-I

[25] Konrad, A.M., Ritchie Jr., J.E., Lieb, P. and Corrigall, E. (2000) Sex Differences and Similarities in Job Attribute Preferences: A Meta-Analysis. Psychological Bulletin, 126, 593-641. https://doi.org/10.1037/0033-2909.126.4.593

[26] Eagly, A. (1987) Sex Differences in Social Behavior: A Social Role Interpretation. Erlbaum, Hillsdale.

[27] Banerjee, B. and McKeage, K. (1994) How Green Is My Value: Exploring the Relationship between Environmentalism and Materialism. Advances in Consumer Research, 21, 147-152.

[28] Saad, G. and Gill, T. (2000) Application of Evolutionary Psychology in Marketing. Psychology \& Marketing, 17, 1005-1034. https://doi.org/10.1002/1520-6793(200012)17:12<1005::AID-MAR1>3.0.CO;2-H

[29] Im, S., Bayus, B.L. and Mason, C.H. (2003) An Empirical Study of Innate Consumer Innovativeness, Personal Characteristics, and New-Product Adoption Behavior. Journal of the Academy of Marketing Science, 31, 61-73. https://doi.org/10.1177/0092070302238602

[30] Vining, J. and Ebreo, A. (1990) What Makes a Recycler? A Comparison of Recyclers and Nonrecyclers. Environment and Behavior, 22, 55-73. https://doi.org/10.1177/0013916590221003

[31] Sandahl, D.M. and Robertson, R. (1989) Social Determinants of Environmental Concern: Specification and Test of the Model. Environment and Behavior, 21, 57-81. https://doi.org/10.1177/0013916589211004 
[32] Maxham, J.G. and Netemeyer, R.G. (2002) Modeling Customer Perceptions of Compliant Handling over Time: The Effects of Perceived Justice on Satisfaction and Intent. Journal of Retailing, 78, 239-252.

https://doi.org/10.1016/S0022-4359(02)00100-8

[33] Anderson, J.C. and Gerbing, D.W. (1988) Structural Equation Modeling in Practice: A Review and Recommended Two-Step Approach. Psychological Bulletin, 103, 411-423. https://doi.org/10.1037/0033-2909.103.3.411

[34] Bagozzi, R.P. and Yi, Y. (1988) On the Evaluation of Structural Equation Models. Journal of the Academy of Marketing Science, 16, 74-94. https://doi.org/10.1007/BF02723327

[35] Bei, L.T. and Simpson, E.M. (1995) The Determinants of Consumers' Purchase Decisions for Recycled Products: An Application of Acquisition-Transaction Utility Theory. In: Kardes, F.R. and Sujan, M., Eds., Advances in Consumer Research 22, Association for Consumer Research, Provo, 257-261.

[36] Dalton, G.J., Lockington, D.A. and Baldock, T.E. (2008) A Survey of Tourist Attitudes to Renewable Energy Supply in Australian Hotel Accommodation. Renewable Energy, 33, 2174-2185. https://doi.org/10.1016/j.renene.2007.12.016 